\title{
Imagens imortalizadas pelas palavras
}

\section{Images immortalized by words}

\author{
Eva Maria Siqueira Alves*
}

\begin{abstract}
RESUMO
Este artigo examina o Atheneu Sergipense, principal instituição oficial de ensino secundário de Sergipe/Brasil, a partir das impressões registradas por aqueles que o visitaram, identificando elementos reveladores de sua estrutura espacial, de seu processo pedagógico e de suas finalidades. O texto destaca, pelas palavras dos seus visitantes, imagens imortalizadas das práticas e do quotidiano escolar daquele centro de formação de vultos que se projetaram no panorama político e intelectual da sociedade sergipana e nacional.

Palavras-chave: Atheneu Sergipense, livro de visitas, Ensino Secundário.
\end{abstract}

\begin{abstract}
This article examines the Atheneu Sergipense, the main official institution of secondary studies in Sergipe/Brazil, from the perspective of the impressions registered by those who visited it, identifying elements of its spacial strucure, pedagogic processes and objectives. The text reveals, by the words of the visitors, images which are immortalized by the school practices of that formation center of men who projected themselves in the political and intellectual life of the state, as well as of the country. Key-words: Atheneu Sergipense, visit book, secondary studies.
\end{abstract}

* Professora Adjunta do Departamento de Educação da Universidade Federal de Sergipe. Mestre em Educação pela Universidade Federal de Sergipe. Doutoranda em Educação pela Pontifícia Universidade Católica de São Paulo. E-mail: evasa@uol.com.br 


\section{O Atheneu Sergipense ${ }^{1}$}

Os primeiros fundamentos para organização dos estudos secundários em Sergipe datam de 1830, quando o Conselho Geral da Província criou as cadeiras de Filosofia, Retórica, Geometria e Francês, não como aulas avulsas, mas centralizadas em um só local, na capital da Província, São Cristóvão, no Liceu Sergipense. Mesmo extinto o Liceu pela Assembléia Legislativa em 1835, continuaram seus professores a lecionar até o ano de 1839 (cf. SEBRÃO, 1954, p. 425). Em 1847, abre-se o segundo liceu, intitulado de Liceu Sergipense, permanecendo nos salões do Convento de Nossa Senhora do Carmo até a mudança da capital para Aracaju, no ano de $1855 .^{2} \mathrm{O}$ Liceu Sergipano, instalado em Aracaju no ano de 1862, teve também duração efêmera.

Mas o anseio por organizar aulas do ensino secundário persistia e apesar das iniciais tentativas de implantação não terem logrado êxito, continuavam os intelectuais de Sergipe a almejar a criação de uma instituição que pudesse agregar as novas gerações políticas e demais membros da burocracia local, reunindo em um só estabelecimento as matérias exigidas nos exames de preparatórios, de modo que "seus filhos não mais necessitassem sair dos limites do seu torrão natal", nas palavras de um relatório do período, para estudar em outras localidades. ${ }^{3}$

Criado pelo Regulamento Orgânico da Instrução Pública de 24 de outubro de 1870, assinado pelo Presidente da Província de Sergipe, o coronel Francisco José Cardoso Júnior, o Atheneu Sergipense oferecia os cursos de Humanidades em quatro anos e o Normal, com dois anos de duração, funcionando concomitantemente no mesmo prédio e com os mesmos professores.

Examinar o Atheneu Sergipense a partir das impressões registradas por aqueles que o visitaram, identificando elementos reveladores de sua estrutura espacial, do seu processo pedagógico e de suas finalidades, é o objetivo deste

${ }^{1}$ Pesquiso no Doutorado os Planos de Estudos do Atheneu Sergipense, compreendidos no período de 1870 a 1908, estudo vinculado ao Projeto de Cooperação Acadêmica - Procad/Capes/ PUCSP/UFS/2001. Para este artigo contei também com o apoio financeiro da Fundação de Amparo à Pesquisa do Estado de Sergipe, por meio do Projeto "Prêmios e sanções como elementos característicos da cultura escolar no Atheneu Sergipense", sob minha coordenação e desenvolvido no período de julho de 2003 a julho de 2004.

${ }^{2}$ Sobre esse tema consultar ALVES (2004).

${ }^{3}$ A escola secundária brasileira, conforme acentua GASPARELLo (2003), surge fundamentada pela força das Humanidades, pelo caráter de preparatório aos cursos superiores e para atendimento das necessidades da cultura da elite. 
estudo, que destaca imagens do Atheneu Sergipense, imortalizadas pelas palavras dos seus visitantes.

Inaugurado festivamente a 3 de fevereiro de 1871, o Atheneu Sergipense iniciou seus trabalhos em um local inadequado para as aulas, o prédio da Câmara Municipal, uma "casa arruinada e suja", segundo relatório do Presidente Joaquim Bento d'Oliveira Júnior (1872). Com algumas contribuições dos "cidadãos mais favorecidos de fortuna", novo prédio foi erguido com "elegância e solidez" na Praça Olímpio Campos, sendo inaugurado em 3 de dezembro de 1872, (cf. nUNEs, 1984). O colégio mudou-se para a Praça Camerino em 1921, para a Avenida Ivo do Prado em 13 de agosto de 1926 e em 1950 para a Praça Graccho Cardoso, aí permanecendo até o momento. ${ }^{4}$

Ao longo dos anos, o Atheneu Sergipense não se modificou apenas por seu espaço físico, pois sofreu também variações quanto à sua denominação: Atheneu Sergipense (1870), Lyceu Secundário de Sergipe (1881), Escola Normal de Dois Graus (1882), Atheneu Sergipense (1890), Atheneu Pedro II (1925), Atheneu Sergipense (1938), Colégio de Sergipe (1942), Colégio Estadual de Sergipe (1943), Colégio Estadual Atheneu Sergipense (1970 aos nossos dias). ${ }^{5}$

Inicialmente com os cursos de Humanidades e o Normal, o Atheneu Sergipense vai, ao longo dos anos, introduzindo novas cadeiras, suprimindo outras e defendendo um método de ensino que estabelecesse conexões diretas entre a teoria e a prática. A preocupação com o lado prático, utilitário, suscitou modificações da estrutura dos cursos, não só quanto ao tempo de duração, mas também quanto aos compêndios, cadeiras e carga horária a elas destinadas.

Assim é que, em 1897, são sete os anos de duração para o curso Integral (cf. DECRETO 231). Em 1908, o curso Ginasial é feito em seis anos (cf. DECRETO 556) e em 1916 quatro são os cursos oferecidos: Ginasial, com cinco anos e destinado aos candidatos aos cursos das escolas de ensino superior da República; Integral, com seis anos, para aqueles que, não podendo ou não querendo seguir as profissões proporcionadas pelos cursos superiores, se destinassem a outros de sua escolha; Normal, com quatro anos, destinando-se exclusivamente aos candidatos ao professorado do ensino primário do sexo

${ }^{4}$ A mudança do Atheneu Sergipense para a Avenida Ivo do Prado em 1926 foi registrada com júbilo por muitos dos vultos que visitaram a instituição, como será analisado adiante.

${ }^{5}$ As datas que estou apresentando foram identificadas nas documentações primárias, e algumas vezes divergem das datas das fontes secundárias. No decorrer do texto, utilizarei a nomenclatura Atheneu Sergipense, salvo quando tratar-se de transcrição, ocasião em que será utilizada a nomenclatura do documento. 
masculino; e o curso Comercial, feito em três anos e destinado aos interessados dos diferentes ramos de negócios (cf. DECRETO 633).

A série de reformas de âmbito federal trazem consideráveis modificações ao Atheneu Sergipense. Em 1936, ano em que se fazem sentir desdobramentos significativos da Reforma Francisco Campos, que traçou novos rumos à educação brasileira, são introduzidos no Atheneu os cursos complementares Pré-médico, Pré-politécnico e Pré-jurídico, de dois anos, posteriores aos seis anos do curso Fundamental (cf. LEI 40). Em 1942, com a Reforma Gustavo Capanema, os cursos passam a ser Ginasial (4 séries), Científico e Clássico (de 3 anos).

O Atheneu Sergipense contava com uma douta Congregação, ${ }^{6}$ que se sentia honrada e orgulhosa por pertencer ao seu grupo, após rigorosos concursos prestados perante mesa examinadora composta de professores da casa sob a presidência do Diretor da Instrução Pública.

As palavras do Bacharel Alfredo Passos, formado na Faculdade de Direito de Recife em 1907, realçam o orgulho de ter sido professor concursado do Atheneu Sergipense, onde também fez o curso de Humanidades (cf. guaraná, 1925). O registro do Promotor Público e colaborador da imprensa em vários Estados aponta elementos a serem analisados, como a estrutura do prédio do Atheneu e seu processo pedagógico.

Não posso calar o sentimento de viva saudade que soffri, ao visitar hoje o novo e nobre edificio em que funciona o Atheneu Pedro II.

Fui parte integrante deste Estabelecimento de ensino secundario, como lente de Historia Universal e do Brasil, desde 14 de fevereiro de 1911 até 15 de julho de 1916. Ficando fóra do exercicio desta cadeira, quiz o destino que eu fizesse, por quasi todo o Brasil, uma extensissima viagem, percorrendo varios Estados do nosso paiz, exercendo sempre, com muita lealdade e dedicação, o magisterio em varias localidades.

Afinal, carregado de desillusão e exhausto de recursos, voltei ao dôce torrão natal. E hoje, nesta casa, tive o inolvidavel orgulho de abraçar muitos dos meus antigos collegas, de travar conhecimento com alguns professores mais moços e de vêr a nova geração que se empluma, cursando as aulas deste Estabelecimento, para a lucta pela existencia. Deixo aqui consignado o meu caloroso elogio aos moldes sobre que assenta o ensino secundario em Sergipe, dispondo de um magnifico

${ }^{6}$ A Congregação do Atheneu Sergipense, órgão de caráter consultivo e deliberativo, constituído pelo grupo de professores da casa e presididos pela Direção. 
edficio, de já muito correcto material escolar e de uma pleiade de professores competentes. Assisti, com muito agrado, as aulas dos professores Leandro Diniz, Clodomir Silva e Santos Mello, recebendo uma impressão profunda dos costumes escolares da minha terra!

Alfredo Passos Cabral. (Livro de Visitas, 5 de setembro de 1929).

O provimento das cadeiras, quando da criação do Atheneu, foi feito pelo Governo, elegendo "as pessoas que mais aptas lhe pareçam para o fim que se pretende”. (Regulamento Orgânico das Instruções Públicas da Provincia de Sergipe, 24 de outubro de 1870, art. 23). As demais cadeiras e vagas que surgiam só poderiam ser preenchidas pela forma de concurso. Os rituais, métodos, personagens, papéis e formas de julgamento são matérias bastante detalhadas nas legislações, que regulamentavam as provas de defesa de uma tese de livre escolha, defesa de tese sobre assunto sorteado, prova prática, quando a natureza da cadeira exigia, e prova oral.

Por esse processo passaram professores com diferentes formações: farmacêuticos, bacharéis, médicos, engenheiros civis, cirurgiões, dentistas, mecânicos e músicos. Ocupavam também outras funções fora do colégio, em diferentes circuitos culturais, tomando assento em cargos legislativos, dirigindo órgãos públicos, como também disseminando suas idéias em constantes artigos publicados na imprensa.

Ser aluno do Atheneu Sergipense era também um excelente caminho para a formação da intelectualidade sergipana e constituía-se orgulho não só daqueles, mas hodiernamente. Dois ex-alunos revelam esse ambiente formador:

Meu coração continua a sentir, ainda aqui, o mesmo ambiente de carinho, de acolhimento, de bem-estar. Tal como si ainda aqui estivessem, vibrando e trabalhando os espiritos infatigaveis de um Teixeira de Faria, de um Alcebíades Paes [...] é o mesmo 'Atheneu Sergipense', onde entrei ha precisamente dezeseis annos, para iniciar a incessante tarefa que ainda não findou, nem é dado saber quando terminará...

João Passos Cabral7 (Livro de Visitas, maio de 1928).

${ }^{7}$ João Passos Cabral estudou no Atheneu Sergipense de 1912 a 1916, onde prestou exames finais das matérias de Humanidades. Trabalhou na imprensa de Aracaju, nos Correios do Estado, tendo colaborado em vários jornais com artigos, poesias, romance e crítica. (As informações biográficas foram coligidas do Dicionário Bio-Bibliográfico de Armindo GUARANÁ, 1925). 
Ao Atheneu the devo o que hoje sei e muito do que agora sou. Foi nelle que formei o espirito com as efficazes lições dos Mestres e salutares conselhos dos amigos.

Antenor Lyrio Coelho ${ }^{8}$ (Livro de Visitas, 24 de julho de 1928).

Esses professores e alunos foram sujeitos que se emplumaram no ambiente de acolhimento, de eficazes lições, de esclarecimento e instrução. $\mathrm{Na}$ casa

...onde outrora se ouvira como raio de sol incendiando a mocidade da sua terra, a palavra brilhante de Tobias Barreto. Possuindo uma douta congregação, o Atheneu Pedro II vae dia a dia esclarecendo, instruindo, enfim alphabetizando a mocidade sadia e brilhante de Sergipe, Sergipe de Tobias Barreto, Sergipe de Fausto Cardoso, Sergipe de Hermes Fontes.

Pereira Reis Junior. (Livro de Visitas, 6 de agosto de 1931).

\section{A materialidade da fonte}

As recentes tendências historiográficas no campo das instituições escolares têm sido marcadas por uma compreensão da escola, das práticas, da cultura escolar, utilizando um diversificado repertório de fontes documentais que permite adentrar nas instituições e captar dispositivos de sua organização. Fontes como legislação, relatórios, atas, correspondências, impressos, compêndios, fotografias, livros de matrículas, provas de concursos, registro de festividades, aliados a novas interrogações, possibilitam, conforme defende CARVALHO (1999), reistoricizar a escola.

Investigando os Planos de Estudos do Atheneu Sergipense foi possível identificar um diversificado acervo documental proveniente do arquivo da

${ }^{8}$ Antenor Lyrio Coelho foi sócio-fundador da Sociedade dos Estudantes de Sergipe, professor da Liga Sergipense contra o Analfabetismo, colaborador com diversos artigos na imprensa sergipana. (cf. Armindo guaranÁ, 1925). 
própria instituição. Destaque-se, dentre outros documentos pertinentes à sua organização, livros como: Livro de Matrículas; Livro de Registro das Correspondências Recebidas e Expedidas; Livro de Registro de Nomeações de Diretores e Professores; Livro de Atas da Congregação; Livro de Atas de Concursos; Livro de Atos de Portarias de Suspensão; Livro de Festividades; Livro de Visitas. ${ }^{9}$

Para este artigo trago à cena uma das peças - o "Livro de Visitas". Mas o que extrair dessa fonte? Que imagens do Atheneu Sergipense são reveladas pelas palavras dos visitantes? As fontes, declara RAGAZZINI, "não falam per se. São vestígios, testemunhos que correspondem - como podem e por um número limitado de fatos - às perguntas que lhes são apresentadas." (RAGAZZINI, 2001, p. 14).

Pesquisas como as de VIDAL (1998), souZA (2001) e MORAES e ALVES (2002) têm utilizado a fotografia como fonte para os estudos da historiografia educacional. A potencialidade das imagens desafia o pesquisador na sua investigação. As imagens aqui investigadas são as reveladas pelas narrativas dos sujeitos que visitaram o Atheneu Sergipense no período de 1916 a 1951 e consignaram suas impressões no "Livro de Visitas". Assim, enfrentar o desafio da interpretação é um exercício de leitura que como a fotografia, emociona, encanta e representa "imagens do passado, que apesar de desterradas do caráter de uma verdade, abrem-se à leitura de múltiplas verdades sobre o ontem." (VIDAL, 1998, p. 86).

O "Livro de Visitas" aberto pelo Diretor do Atheneu Sergipense Dr. Aristides da Silveira Fontes, objetivando registrar as impressões daqueles que desejavam visitar o Atheneu, ou que eram convidados para tal, contém 88 páginas manuscritas e recebeu sua primeira declaração do Diretor Geral da Instrução Pública Helvécio de Andrade:

Levo da visita que acabo de fazer ao Atheneu Sergipense, em companhia do cidadão secretario da Instrução Publica, e a convite do respectivo director, a melhor impressão. Posso bem avaliar das modificações aprovadas no estabelecimento, eu que o conheci há alguns annos, como Delegado Fiscal do Governo Federal junto ao mesmo estabelecimento, quando equiparado ao Gymnasio Nacional. A fecunda direção do illustre

\footnotetext{
${ }^{9}$ Cabe dizer que as fontes provenientes do arquivo do Atheneu Sergipense não foram as únicas investigadas. Em diferentes locais, como o Instituto Histórico e Geográfico de Sergipe e na Biblioteca Pública Epifâneo Dórea, foram obtidos sinais das práticas daquela instituição.
} 
professor Dr. Aristides Fontes e ao auxilio não menos ficando do seu activo e intelligente secretario, cidadão João de Góes, vê-se seu esforço, deve o Atheneu a nova phase de prosperidade em que francamente entrou, tudo em correspondencia com os vistos superiores do justo claro cidadão que ora dirige os negocios do Estado, S. Exc. O sr. Durval Oliveira Valladão, de um patriotismo tão denso quanto dedicado á causa da Instrução Publica.

Aracaju, 3 de agosto de 1916

Dr. Helvécio de Andrade

Director G. da Inst. Publica

Raymundo Ribeiro

Secretario da Instrucção Publica

Com um total de 117 registros, o livro representa, porém, um maior número de visitantes, uma vez que alguns subscrevem declarações de outros, como nos casos das Embaixadas que por lá passaram ${ }^{10}$ : Embaixada Gustavo L'Metra com 32 membros em 1935; Embaixada de Alunos do Curso Complementar de Medicina da Bahia, com 19 membros em 1940; Embaixada Dr. Lauro Farani, em 1949 com 21 membros; Alunos da 3. a série científica do Colégio Estadual da Bahia, com 20 membros em 1951; 18 membros da Escola Técnica de Comércio Epitácio Pessoa da Faculdade de Ciências Econômicas da Paraíba, em 1951; 25 Congressistas do IV Congresso Estadual dos Estudantes Secundários, em 1951; Embaixada Estudantil do Colégio Guido Fontgaland, com 15 membros, em 1951. ${ }^{11}$

Os visitantes compunham-se de autoridades políticas, governadores, membros do clero, ex-alunos, ex-professores, desembargadores, jornalistas, delegados, militares, grupos de estudantes, cônsules, inspetores escolares, diretores de órgãos públicos, que não se esquivavam por consignar suas impressões, suas avaliações com elogios ou críticas ao Atheneu Sergipense.

${ }^{10}$ As excursões pedagógicas denominadas "Caravanas" ou "Embaixadas" constituíam-se atividades suscitadas pelas direções, tanto para receber no Atheneu Sergipense embaixadas de outros Estados, como também para proporcionar que os estudantes transpusessem "as fronteiras sergipanas em missão de confraternização e intercâmbio cultural.” A primeira do Atheneu Sergipense foi com a caravana denominada "Alcebíades Paes", quando os ginasianos do Atheneu, chefiados pelo Diretor Joaquim Vieira Sobral, visitaram o Estado da Bahia, em 1936. (cf. sobral, 1936).

${ }^{11}$ Cabe dizer que nos anos de 1919, 1920, 1921, 1922, 1925, 1926, 1938, 1942, 1943,1946 e 1947 não há registros de visitas nesse documento, o que não significa dizer que o Atheneu Sergipense não tenha sido visitado nesses anos. 
Encerra o livro, em 8 de novembro de 1951, a enfermeira do Serviço Especial de Saúde Pública (Sesp) ${ }^{12}$ a senhora Beatriz Semington:

Levo uma ótima impressão do Colégio Estadual de Sergipe, e do grande esforço em prol da juventude desta muito acolhedora terra sergipana.

Assim, esquadrinhando o "Livro de Visitas" e relacionando-o a outras fontes examinadas, identifico-o como importante fonte de pesquisa para os estudos da historiografia educacional, pois exprime, pela palavra escrita, o que testemunharam seus visitantes - múltiplas faces das práticas educacionais do Atheneu Sergipense.

\section{Com a palavra, os visitantes}

Folgo de registrar aqui a agradável impressão que sinto ao visitar este notavel instituto de ensino. Tanto pela sua organização e ordem interna, pelo modo como é dirigido, pela excelencia do pessoal docente, como

${ }^{12}$ Criado durante a 2. ${ }^{a}$ Guerra Mundial, como consequiência do convênio firmado entre os governos brasileiro e norte-americano, o Sesp tinha como principal objetivo sanear a Amazônia e a região do Vale do Rio Doce. Atuou também na formação de profissionais da saúde, implantando e desenvolvendo escolas de enfermagem. A partir da década de 1950, o Sesp criou o Programa do Vale do Rio São Francisco, com o objetivo de atender a diversas localidades dos Estados de Alagoas, Pernambuco, Bahia, Minas Gerais e Sergipe. Em 1960, transformou-se em Fundação Serviço de Saúde Pública, expandindo a atuação. A partir de 1990, a Fundação Sesp foi extinta. (Pesquisa realizada no site http://www.fundo-sesp.htm, em 02/02/2004). 
pela propriedade do mobiliario e de todos os apparelhos escolares, julgo que o Atheneu Sergipense é um estabelecimento, no governo, modelar, e deve ser um justo motivo de ufania e orgulho para Sergipe, Estado pequeno, sim, pelo território, mas dos maiores da União pelo espirito do seu povo. É com immenso prazer que consigno aqui a minha admiração pelos que ensinam nesta casa; e congratulo-me, portanto, com a futura geração pela fortuna de estar aqui recebendo o maximo do espititual patrimonio que lhe póde dar a geração actual.

A todos meus applausos e os meus votos.

Rocha Pombo (Livro de Visitas, 25 de Agosto de 1917).

Os registros, pela palavra escrita, constituem fontes reveladoras da cultura do Atheneu Sergipense e da formação do imaginário que o envolve como um "tradicional solar da intelligencia sergipana [...] onde imperam os raios ilutares e necessarios princípios da Ordem, da Hygiene e da Disciplina. (Costa Filho, Livro de Visitas, 9 de agosto de 1916), tornando-a assim "uma das melhores casas de ensino do Norte do Brasil". (Capitão J. Franco Cabral, Livro de Visitas, 17 de agosto de 1916).

Nas palavras dos visitantes, afloram aspectos do cotidiano escolar revelados pelas impressões causadas pela estrutura do prédio, do processo pedagógico, do mobiliário e aparelhos escolares, da administração da escola, dos fins educacionais do estabelecimento e das aulas assistidas.

Uma das faces testemunhadas pelos visitantes diz respeito ao ambiente em que as aulas eram ministradas, com "pequenez do seu edifício e as relativamente inferiores condições para seu funcionamento" (Silva Vianna, Livro de Visitas, 7 de agosto de 1918). O elemento espaço é um dos itens de constantes críticas feitas pelos diretores do estabelecimento quando dos relatórios anuais. Queixavam-se alegando não terem espaço suficiente para realizar algumas atividades, como aulas de ginástica, recreio, ou reclamavam das instalações sanitárias precárias.

Em 1925, o Atheneu Sergipense passa a denominar-se Atheneu Pedro II em homenagem ao centenário de nascimento do ex-imperador do Brasil. Em 13 de agosto de 1926, novo prédio foi inaugurado com a presença do presidente eleito da República, Dr. Washington Luiz, do Governador do Estado, Graccho Cardoso, e demais autoridades locais. No novo prédio os professores passaram a ter um "ambiente propicio á magnitude do seu apostolado", uma vez que para o signatário "nunca haveria bom ensino, sinão em boa casa". (Cláudio, Livro de Visitas, 7 de abril de 1927). ${ }^{13}$

\footnotetext{
${ }^{13}$ Não foi possível identificar o sobrenome do autor.
} 
Edifício modelarmente construído, com as suas classes espaçosas, a aeração necessária e a mais adequada distribuição de luz, que é dado imaginar-se, com o seu material pedagógico e mobiliario escolar modernos, representa uma das mais notorias contribuições ao progresso da instrucção publica secundaria de Sergipe.

Alfredo Martins (Livro de Visitas, 16 de dezembro de 1927).

Não somente por suas "disposições estheticas, mas sobretudo, pelo que offerece de hygiene e conforto e pelo muito que está apparelhado a fazer pela instucção secundaria de Sergipe." (Antônio Felizola, Livro de Visitas, 11 de outubro de 1927). Nesse mesmo sentido, Maria de Lourdes Muniz Barreto declara ser o Atheneu Pedro II uma casa de educação secundária bem adaptada aos fins a que se propunha, "pela sua imponente construcção architetonica", como também "pela intelligente distribuição de luz e ar nos seus diversos e vastos salões de aulas" (4 de fevereiro de 1928).

Os discursos médico-higienistas influentes no campo educacional iniciaram, desde o século XIX, debates em torno das questões quanto aos espaços pedagógicos destinados às aulas. Ao tempo em que criticavam as péssimas condições do saneamento básico, da escassez de água encanada, os higienistas acentuavam a necessidade de terem as escolas instalações próprias para funcionamento, com espaços amplos, boa iluminação e mobiliário apropriado.

Outros são os que seguem avaliando positivamente o novo espaço pelo edifício moderno, de relevo e destacado dentre os demais edifícios públicos da cidade de Aracaju, simbolizando o progresso cultural, com boa disposição de iluminação e ar, obedecendo às melhores regras de higiene, asseio e conforto, "com sua limpeza irreprehensivel, sem um rabisco ou desenho nas paredes de suas amplas, claras e ventiladas" salas de aulas (Geonísio Curvelo de Mendonça, Livro de Visitas, 30 de novembro de 1928) e boa organização administrativa. ${ }^{14}$

Entretanto, mesmo com essa gama de avaliações positivas quanto ao ambiente e ao local das aulas, críticas não foram poupadas. $\mathrm{O}$ inspetor do curso complementar Pré-Médico, Dr. Herbert Parente Fortes, assim se expressa:

${ }^{14}$ Antes de emitir essa opinião, Geonísio Curvelo, declarando-se um "positivista convencido", pede licença e transcreve reflexões de Augusto Comte. Termo de Visita também publicado no Diário Oficial do Estado de Sergipe, em 5 de dezembro de 1928. 
Alguns reparos, sempre possíveis em relação a construcções desse gênero, como a falta de área coberta, de recreio e campos de esportes, as dimensões das janellas exteriores, e numero proporcional de serviços hygienicos.

No entanto, segundo o próprio inspetor, tais defeitos não diminuíam o prazer e ótima impressão que do estabelecimento teve. Sugeria ainda às autoridades do Estado de Sergipe que aumentassem os ordenados do magistério secundário do Atheneu, "porque se é certo que nem só de sacrifícios há de sempre viver o mestre". (Herbert Fortes, Livro de Visitas, 30 de março de 1937).

O processo pedagógico desenvolvido no Atheneu Sergipense pode ser apreendido também por meio das impressões registradas daqueles que o visitaram, pois a eles era proporcionado assistirem a exames e aulas regulares, observando não só

...a grande competencia de seus detentores, a excellencia dos seus methodos de ensino, a facilidade de suas exposições, mas tambem o aproveitamento admiravel e admirado dos alumnos que são, em verdade, o reflexo dos mestres, salvo as excepções oriundas de fatores outros.

Antonio Dias de Moraes (Livro de Visitas, 10 de setembro de 1929).

Convidado para assistir às aulas de Latim do professor Pe. Possidonio Rocha e de Francês do Dr. Leandro Diniz, o advogado Francisco Antonio de Carvalho Lima Junior assim se expressou:

O primeiro, pela sua competência, fez recordar o antigo mestre Tobias Barreto, pela facilidade da exposição; e o segundo representa perfeitamente as tradições de Geminiano Paes na cadeira de mestre e pedagôgo.

Na aula de Latim destinguiu-se uma jovem alumna; na de Francez, dous intelligentes rapazes. Em geral fiquei captivo de todos os lentes a quem fui apresentado, e de todos os funcionarios.

Francisco Antonio de Carvalho Lima Junior (Livro de Visitas, 8 de agosto de 1916). ${ }^{15}$

${ }^{15}$ Carvalho Lima Junior, poeta e compositor, fez o curso Normal no Atheneu Sergipense (1875), e tomando gosto pelo jornalismo publicou muitos artigos na imprensa de Alagoas e Sergipe. Desligando-se do funcionalismo público, dedicou-se à propaganda republicana. (cf. GUARANÁ, 1925). 
Para Paulo Assumpção, do Ministério da Agricultura, das aulas que assistiu encantaram-lhe "a elevação do ensino ministrado e a intelligencia e adeantamento dos alumnos argüidos, o que tudo faz do Atheneu Sergipense um dos mais notaveis gymnasios da Republica."(Livro de Visitas, 14 de agosto de 1916). O Barão Homem de Melo também se fez presente em visita ao Atheneu Sergipense, escrevendo:

Visitando hoje este estabelecimento de instrucção secundaria tive oportunidade de notar a excellente e criteriosa direç̧ão do seu actual Director Dr. Aristides da Silveira Fontes e tambem a competencia dos professores que compoem o Corpo Docente de tão notavel casa, que historica e tradicional já se tornou no conceito da Instrucção publica nacional, taes as distinctas e gloriosas gerações de intellectuaes que tem por aqui passado.

Tive a ventura de assistir uma aula de francez leccionada pelo provecto professor Dr. Leandro Diniz de Faro Dantas, cuja competencia na disciplina de que é cathedratico me fez evocar a sabedoria do eminente e saudoso lente de francez, meu estimado collega Habbout, no antigo Collegio Pedro $2^{\circ}$.

Barão Homem de Melo (Livro de Visitas, 13 de março de 1917).

José Rodrigues da Costa Dórea, ex-Governador de Sergipe (24 de outubro de 1908 a 4 de outubro de 1911), visitando o Atheneu assistiu às aulas de:

Arithmetica sob a regencia do professor Abdias Bezerra, a de francez lecionada pelo Dr. Leandro Diniz, e a de Historia professada pelo lente Arthur Fortes, e dellas sahi satisfeito pela proficiencia e interesse dos mencionados docentes o que não foi sorpresa para mim.

Rodrigues Dórea (Livro de Visitas, 28 de setembro de 1917).

Para atingir as metas apregoadas como fins principais da instituição proporcionar à mocidade a instrução necessária e suficiente para a matrícula nos cursos superiores, bem como para o bom desempenho das funções na vida social -, os professores do Atheneu Sergipense desenvolviam lições dentro do método prático e intuitivo, partindo do concreto para o abstrato, do definido para o indefinido, do simples para o composto, do particular para o geral. 
Por determinação legal, devia o Atheneu contar para o regular funcionamento das aulas com uma biblioteca e um museu, meios esses indispensáveis para a eficiência dos estudos. Em 1921, possuía a instituição museu, biblioteca, gabinetes de Física, Química e História Natural, de modo que os programas de ensino fossem desenvolvidos com aplicações práticas. Em 1926, o Governo autoriza a reorganização dos gabinetes de Física e História Natural, o laboratório de Química e a adquirir os instrumentos precisos para o ensino de Geografia, Cosmografia e Desenho, abrindo desta sorte os necessários créditos.

No Governo de José Rodrigues da Costa Dórea, foram adquiridos "aparelhos e mais utensílios que vieram da Europa para os gabinetes de História Natural, Mechanica, Astronomia e Geografia". (Correio de Aracaju, 19 de novembro de 1909), mas que, ao que parece, não foram suficientes, queixando-se o diretor Leandro Diniz no seu relatório de 1926, no que chamava a atenção do Governo para o fato de que o Atheneu poderia ser prejudicado pela Inspeção Fiscal.

Devemos pois contar com a sua presença em Aracaju, brevemente, e a equiparação do Atheneu estará comprometida, perdê-la-íamos, com certeza, se o Dr Paranhos da Silva não encontrar no nosso ginásio, gabinetes de física, química, história natural, geografia e cosmografia, nem ao menos levasse daqui a certeza de que o governo já havia providenciado para a sua aquisição. Acresce que o Dr. Bernardino José de Souza, que fora comissionado, como delegado daquele Departamento, para fiscalizar, em março último, os exames de $2^{\mathrm{a}}$ época do Atheneu, em seu relatório frizou, com justiça neste ponto, essa deficiência do nosso instituto, expondo-nos assim, a um perigo que agora se repete com a esperada inspeção. (Leandro Diniz do Faro Dantas, 13 de julho de 1926).

É certo que, mesmo havendo atenção por parte do governo em instituir na legislação elementos necessários para uma eficiente formação, havia, nas palavras dos diretores, reclamações quando seus pleitos não eram atendidos. A avaliação externa adquire um caráter de aliado às reivindicações da Direção ao Governo. São as falas dos dirigentes que pedem para instituir no Atheneu Sergipense um ambiente propício formador da intelectualidade sergipana. ${ }^{16}$

\footnotetext{
${ }^{16}$ As afirmações estão fundamentadas nos ofícios e relatórios transcritos no Livro das Correspondências do Atheneu Sergipense.
} 
Uma outra face que atraia a atenção dos visitantes era a dos gabinetes e laboratórios de Física e Química e História Natural, especialmente porque, segundo Alberto Andrada, professor da Escola de Minas de Ouro Preto, de costume, esses laboratórios eram

os mais pobres quando existem, nos gymnasios do Norte e tambem do Sul do Paiz. Alegrei-me por vel-os no Atheneu Sergipense, pequenos porem perfeitamente apparelhados para o fim didactico a que se propõem. Fica assim, o estudo da Physica e da Chimica reconduzido á sua verdadeira orientação: a Physica ensinada semelhante á Physica creada, em que o phenomeno e a experiencia são o pedestal de tudo. Em torno destes e sobre estes é que se constroem as theorias que explicam e, freqüentemente, os trazem á luz, theorias tão subordinadas aos factos concretos, aos phenomenos que um só destes, que por ellas seja inexplicavel a as contradiga, basta para as lançar por terra.

Seguindo a mesma sequencia, a Physica estudada só será sabida da verdade si o phenomeno visto der razão da theoria que o explica. O apparelhamento do laboratorio de Physica e Chimica do Atheneu Pedro II já permite que os conhecimentos dessas disciplinas vão se erguendo na mente do alumno equilibradamente, numa verdadeira construcção segura que se forma de factos sobre factos, argamassados pelas theorias que os reúnem e os ligam num todo organico que é a Physica.

Alberto Andrada (Livro de Visitas, 30 de junho de 1933).

Esses gabinetes, avaliados como modernos, equipados, atendendo às necessidades dos programas e finalidades experimentais, possibilitavam à mocidade sergipana "o auxilio que a orientação do ensino actual requer." (Alberto de Souza, Livro de Visitas, 30 de março de 1931). Para a Embaixada Neves da Rocha, era mister a qualidade, sobretudo material e intelectual de um estabelecimento de ensino, completando o Atheneu Sergipense sua obra educativa, selecionando por concurso "o seu professorado, conscio de que somente com mestres competentes é que se póde ministrar ensino eficiente e são (15 de outubro de 1940).

"A razão de ser o Colegio Estadual de Sergipe um dos focos luminosos da cultura e da intelligencia sergipana" se devia, segundo Oliveira Filho, diretor do colégio Santanópolis - Feira de Santana/BA, em 14 de novembro de 1944, aos seus gabinetes, ao material pedagógico, à capacidade do corpo docente, à disciplina dos discentes, à organização da diretoria, à boa vontade 
dos auxiliares, enfim, a um conjunto de medidas e ações inerentes àquela instituição.

Por fim, pelos sinais, pelas palavras dos visitantes, a imagem revelada do Atheneu Sergipense pode ser sintetizada na fala de Hermes Fontes.

Muito agradável, muito impressivo e sobretudo muito animador, tudo que acabo de ver e observar nas fundações, instalações e objetivo do "Atheneu Pedro II".

Casa do amanhã sergipense, pois que lhe cumpre a preparação da psyche das novas gerações, não basta conserval-o e mantêl-o, sinão e, principalmente melhoral-o e amplial-o da sua destinação inicial áqueles seus mesmos obcjetivos, que, de futuro, talvez não sejam os mesmos e hoje.

Os novos pavilhões, o conjunto de apparelhos e estudos, o programma supplementar, nas instalações e nos trabalhos com que o actual governo entra a rever e completar o anterior entremostram perfeitamente que os homens de Sergipe já conhecem que instruir e construir, differentes em prefixação, se igualam e se transubstanciam num mesmo verbo alviçareiro de consciencia e liberdade, de beleza e de nobreza, de utilidade e de progresso.

Hermes Fontes (Livro de Visitas,12 de março de 1929).

A relevância conferida aos visitantes e conseqüentemente ao que consignavam no "Livro de Visitas" pode ser apreendida pelo fato de que as impressões nele registradas eram também transcritas e publicadas no Diário Oficial do Estado de Sergipe e na imprensa local. Por esses meios, suas palavras imortalizavam o Atheneu Sergipense, a si mesmos e suas próprias impressões. 


\section{REFERÊNCIAS}

ALVES, E. M. S. Laudas do Lyceu Sergipense (1848-1851). In: ENCONTRO REGIONAL DE HISTÓRIA, 17., 2004, Campinas. Anais... Campinas: Unicamp. 1 CDROM.

CARVALHO, M. M. C. de. Por uma história cultural dos saberes pedagógicos. In: CATANI, D. B.; SOUZA, C. P. Práticas educativas, culturas escolares, profissão docente. São Paulo: Escrituras, 1999.

CORREIO DE ARACAJU. Aracaju, 19 nov. 1909.

DIÁRIO OFICIAL DO ESTADO DE SERGIPE. Sergipe, 1919-1931.

GASPARELLO, A. M. O paradoxo republicano: um modelo secundário nacional nos limites da descentralização. In: REUNIÃO ANUAL DA ASSOCIAÇÃO NACIONAL DE PESQUISA EM EDUCAÇÃO, 26., 2003, Poços de Caldas. Anais... 1 CDROM.

GUARANÁ, A. Diccionario Bio-bibliografico Sergipano. Rio de Janeiro, 1925.

LIVRO de Recortes do Diário Oficial do Estado de Sergipe (publicações referentes ao Atheneu Sergipense - 1928 a 1939).

MORAES, C. S. V.; ALVES, J. F. Escolas profissionais públicas do estado de São Paulo: uma história em imagens. São Paulo: Centro Paula Souza, 2002.

NUNES, M. T. História da educação em Sergipe. Rio de Janeiro: Paz e Terra, 1984.

RAGAZZINI, D. Para quem e o que testemunham as fontes da história da Educação? Educar em Revista, Curitiba: UFPR, n. 18, 2001.

SEBRÃO, S. Laudas da história do Aracaju. Aracaju: Prefeitura Municipal, 1954.

SERGIPE. Regulamento Orgânico da Instrução Pública de Sergipe de 24 de outubro de 1870. ARACAJU: Typ. do Jornal do Aracaju, 1870.

SERGIPE. Decreto n. 231, de 9 de julho de 1897. Compilação das Leis, Decretos e Regulamentos do Estado de Sergipe, v. iv (1897-1898), p. 227-281.

SERGIPE. Decreto n. 556, de 24 de agosto de 1908. Coleção Leis e Decretos, Aracaju: Imprensa Oficial, 1926, p. 16-40.

SERGIPE. Decreto n. 633, de 17 de junho de 1916. Coleção Leis e Decretos, Aracaju: Imprensa Oficial, 1926, p. 323-366.

SERGIPE. Lei n. 978, de 10 de novembro de 1926. Coleção Leis e Decretos, Aracaju: Imprensa Oficial, 1926. 
SERGIPE. Lei n. 40, de 18 de novembro de 1936. Diário Oficial de Sergipe, ano xviii, n. 6.624.

SOBRAL, J. V. Anuário do Atheneu Pedro II. Aracaju: Casa Ávila, 1936.

SOUZA, R. F. de. Fotografias escolares: a leitura de imagens na história da educação primária. Educar em Revista, Curitiba: UFPR, n. 18, 2001.

VIDAL, D. G. A fotografia como fonte para a historiografia educacional sobre o século XIX: uma primeira aproximação. In: FARIA FILHO, L. M. de. Educação, modernidade e civilização. Belo Horizonte: Autêntica, 1998.

\section{Manuscritos}

LIVRO de Visitas (1916-1951).

LIVROS das Correspondências Expedidas do Atheneu Sergipense, v. 1916-1922, v. 1922-1932.

LIVROS das Correspondências Recebidas, v. 1916-1922, v. 1917-1923, v. 1924-1927, v. 1928-1937.

Texto recebido em 30 de jun. 2004 Texto aprovado em 23 de set. 2004 